OPEN ACCESS

Edited by:

Willa Ann Hsueh,

The Ohio State University,

United States

Reviewed by:

Xuanjun Wang,

Yunnan Agricultural University, China

Ka Man Law,

University of California, Los Angeles,

United States

${ }^{*}$ Correspondence:

Jacqueline M. Stephens

jsteph1@Isu.edu

Specialty section:

This article was submitted to

Inflammation,

a section of the journal

Frontiers in Immunology

Received: 30 September 2020

Accepted: 31 December 2020

Published: 29 March 2021

Citation:

Sanchez-Infantes D and Stephens JM (2021) Adipocyte Oncostatin Receptor

Regulates Adipose Tissue Homeostasis and Inflammation.

Front. Immunol. 11:612013.

doi: 10.3389/fimmu.2020.612013

\section{Adipocyte Oncostatin Receptor Regulates Adipose Tissue Homeostasis and Inflammation}

\author{
David Sanchez-Infantes ${ }^{1,2}$ and Jacqueline M. Stephens ${ }^{3 *}$ \\ ${ }^{1}$ Department of Endocrinology and Nutrition, Germans Trias i Pujol Research Institute, Barcelona, Spain, ${ }^{2}$ Department of Basic \\ Sciences of Health, Area of Biochemistry and Molecular Biology, Universidad Rey Juan Carlos, Alcorcon, Spain, ${ }^{3}$ Department of \\ Biological Sciences and Pennington Biomedical Research Center, Louisiana State University, Baton Rouge, LA, United States
}

Adipocytes are the largest cell type in terms of volume, but not number, in adipose tissue. Adipocytes are prominent contributors to systemic metabolic health. Obesity, defined by excess adipose tissue (AT), is recognized as a low-grade chronic inflammatory state. Cytokines are inflammatory mediators that are produced in adipose tissue (AT) and function in both AT homeostatic as well as pathological conditions. AT inflammation is associated with systemic metabolic dysfunction and obesity-associated infiltration and proliferation of immune cells occurs in a variety of fat depots in mice and humans. AT immune cells secrete a variety of chemokines and cytokines that act in a paracrine manner on adjacent adipocytes. TNF $\alpha, \mathrm{IL}-6$, and MCP-1, are well studied mediators of AT inflammation. Oncostatin $\mathrm{M}(\mathrm{OSM})$ is another proinflammatory cytokine that is elevated in AT in human obesity, and its specific receptor (OSMR $\beta$ ) is also induced in conditions of obesity and insulin resistance. OSM production and paracrine signaling in AT regulates adipogenesis and the functions of AT. This review summarizes the roles of the oncostatin $M$ receptor (OSMR $\beta$ ) as a modulator of adipocyte development and function its contributions to immunological adaptations in AT in metabolic disease states.

Keywords: adipocyte, OSM, Inflammation, OSM receptor, fat, adipose tissue, insulin resistance

\section{INTRODUCTION}

The global obesity rate has nearly doubled since 1980 (1). This high incidence poses a massive economic burden on healthcare systems. More importantly, obesity is frequently accompanied by adverse metabolic effects including hypertension, dyslipidemia, fatty liver, insulin resistance and type 2 diabetes (T2D) (2). In addition, obesity (3) and T2DM (4) are prominent risk factors for the severity of COVID-19 infections. Although obesity is a threat to global health, treatment options remain limited, and they are often ineffective or invasive (e.g. bariatric surgery) (5).

Obesity occurs when energy intake exceeds energy expenditure, but this relationship is complex, as many factors influence these two parameters. Positive energy balance causes WAT to expand by adipocyte hyperplasia, hypertrophy, or a combination of these processes. In addition to lipid storage, adipocytes have important endocrine functions whereby they secrete hormones (leptin, adiponectin, etc.), microRNAs, exosomes, and lipids that contribute to systemic metabolic health (6). There is evidence that the release of proinflammatory cytokines, such as Tumor Necrosis Factor $\alpha(\mathrm{TNF} \alpha)$ and Monocyte chemoattractant protein 1 (MCP-1) that can occur in obesity is driven by 
stress responses related to WAT expansion, although specific mechanisms involved remain to be elucidated (7).

In addition to adipocytes, there are several other cell types within WAT, including different types of macrophages and $\mathrm{T}$ cells. The non-adipocyte cells in AT, such as immune, endothelial, perivascular, and stromal cells, as well as preadipocytes, collectively comprise the stromal vascular fraction (SVF). The cell numbers of the SVF are greater than number of adipocytes in white adipose tissue depots. Obesity is associated with changes in the relative abundance and activation states of various immune cell subpopulations in AT, as well as with altered endocrine properties of adipocytes themselves. Many of the proinflammatory cytokines produced in AT act in a paracrine manner and typically do not contribute to circulating levels of these signaling mediators. Proinflammatory cytokines made in AT can inhibit adipocyte differentiation and induce insulin resistance in adipocytes, and modulation of both these processes in AT has systemic effects (8-10). Although less studied than other AT cytokines, OSM clearly contributes to AT homeostasis (11-13), and increased OSM levels in AT promote systemic metabolic dysfunction through effects on both adipocyte development and adipose tissue function.

\section{OSM AND ITS SPECIFIC RECEPTOR OSMRB: SOURCE AND BIOLOGY}

The gp130, or interleukin (IL)-6, family is a group of structurally similar cytokines that includes IL-6, IL-11, IL-27, neuropoietin, leukemia inhibitory factor (LIF), OSM, cardiotrophin-1, ciliary neurotrophic factor, and novel neurotrophin-1/B cell stimulating factor-3 or cardiotrophin-like cytokine (14). These cytokines regulate a variety of complex biological processes, including hematopoiesis, immune responses, inflammation, stem cell potency, mammalian reproduction, cardiovascular action, and neuronal survival (15). Also, gp130 cytokines have been proposed as potential therapeutic targets for obesity treatment (16). Hence, there is a strong rationale for studying gp130 cytokines in modulating metabolic processes in WAT and other tissues involved in obesity and related diseases.

All members of the IL-6 cytokine family require glycoprotein 130 (gp130) as a common signal transducer in their receptor complexes. Unlike other gp130 cytokines, OSM has its own specific receptor (OSMR $\beta$ ) that heterodimerizes with gp130 but is not used by other gp130 cytokines (17) and mediates the majority of OSM effects. OSM and LIF evolved by gene duplication relatively recently (18), and they share substantial sequence identity (19). Though originally identified for its ability to inhibit cancer growth in humans (20), OSM can modulate a variety of other biological processes, including liver development and regeneration $(21,22)$, hepatic insulin resistance and steatosis (23), inflammation (24), and cardiomyocyte dedifferentiation and remodeling (25). There is some evidence that OSM is the only gp130 cytokine with the unique ability to signal through two distinct receptor units-the gp130/LIFR (26) and the gp130/OSMR $\beta$ complex (17). However, other studies have shown that murine OSM signals only through the gp130/ OSMR $\beta$ receptor complex (27-29).
OSM is produced by activated T cells and macrophages (20, 30,31 ), and elevated OSM levels are found in a variety of inflammatory diseases in humans, including inflammatory bowel disease, rheumatoid arthritis, cancer, and obesity (12, 32-35). Our own research has shown that OSM is present in the SVF of AT, but not in adipocytes (11). Purification of immune cells in AT revealed that $\mathrm{T}$ cells and macrophages were the main sources of OSM in adipose tissue in mice (36). Although OSM is produced in immune cells, the OSM receptor (OSMRß) is present in both adipocytes and immune cells (36). However, upregulation of OSMRß expression by high-fat diet is observed only in adipocytes (36).

\section{EFFECTS OF OSM-OSMRß INTERACTION IN PATHOLOGICAL CONDITIONS}

The molecular signaling caused by OSM-OSMR $\beta$ interaction has been suggested to modulate several inflammatory processes, including obesity-related insulin resistance $(11,13)$. One of several mechanisms involved in the ability of excess OSM to promote metabolic dysfunction is the control of adipogenesis. Inhibition of fat cell differentiation and adipose tissue expansion has been recognized as a causative factor for insulin resistance for over twenty years (37). Indeed, factors that inhibit adipogenesis, including OSM, tumor necrosis factor alpha and interferon gamma have been shown to have metabolically unfavorable effects such as insulin resistance (38). It is well established that OSM inhibits adipocyte development of both brown and white adipocytes in vitro (39-41). Mice with a global deletion of OSMR $\beta$ have increased adipose tissue mass (42), supporting the concept that OSM acts to inhibit adipocyte development and that lack of OSM signaling leads to increased AT expansion. There is also evidence to suggest that OSM treatment of mice reduces body weight and adiposity $(42,43)$. However, it should be noted that the OSM doses used in these mouse experiments were very high (12.5 $\mathrm{ng} / \mathrm{g}$ body weight, administered twice daily) and may have caused indirect effects on fat mass. The anti-adipogenic effects of OSM have also been shown in human preadipocytes (13). In regard to the molecular mechanisms involved in the impairment of adipogenesis, OSM has been shown to inhibits C/EBP $\alpha$ and $\operatorname{PPAR} \gamma$ (peroxisome proliferator-activated receptor $\gamma$ ) expression, two key transcription factors involved in adipogenesis $(40,44)$. In terms of modulation of lipid and glucose homeostasis, the antiadipogenic effects of OSM could have systemic consequences. In addition to AT, the liver is an essential metabolic organ for lipogenesis, lipid uptake, and fatty acid b-oxidation and liver is responsive to OSM signaling (45). Some studies show that the OSMR $\beta$ expression levels negatively correlate with mRNA levels of gluconeogenic genes. Moreover, OSMR $\beta$ ablation lead to decreased levels of genes related to cholesterol efflux and fatty acid $\beta$-oxidation, and increased expression of genes that regulate cholesterol synthesis, fatty acid synthesis, and uptake (45). Hence, it is likely that OSM promotes inflammation and metabolic dysfunction at least in part by inhibiting the development of new adipocytes., but there is also evidence to show OSM also regulates lipid metabolism pathways in the liver. 
In addition to regulating adipocyte differentiation, OSM has been proposed to contribute to AT immune response. In contrast to IL-6 which is directly induced through the TLR-nuclear factor $\mathrm{k}-\mathrm{B}$ pathway (46), OSM is secreted by activated macrophages through a PGE2-cyclic adenosine monophosphate- protein kinase A pathway $(47,48)$. In adipose tissue from obese mice, OSMRß has been reported to be increased in the SVF, especially in the F4/80-positive ATMs (adipose tissue macrophages), suggesting that OSM signaling is strongly associated with the pathogenesis of obesity and related metabolic disorders (43). OSM binding to OSMRß modulates inflammatory states, both in vitro and in vivo. Expression of stromal cell-derived factor 1 alpha (SDF-1 $\alpha$ ) has been reported to be suppressed by OSM treatment of adipocytes (49). SDF-1 $\alpha$, also known as CXCL12, regulates the trafficking of bone marrow progenitor cells, as well as the transendothelial migration of leukocytes $(50,51)$. Further studies are required to determine whether altered SDF-1 levels play a role in mediating OSM's effects on homeostasis or metabolic dysfunction. In addition to SDF-1, there is evidence that plasminogen-activator inhibitor 1 (PAI1) is also directly regulated by OSM (11). The ability of OSM to induce PAI1 is dependent on OSMRß expression in cultured murine adipocytes (11). Although SDF-1 and PAI-1 may play a role in OSM function in AT, no rigorous studies have identified or directly evaluated OSM-regulated genes in adipocytes. Interestingly, in vitro experiments in brown adipocytes have demonstrated that OSM signaling via the OSMRß results in an increase in TNF $\alpha$ and MCP-1 (or C-C Motif Chemokine Ligand 2, Ccl2) mRNA levels, and interleukin 6 protein and each of these cytokines are involved in the recruitment and activation of macrophages in AT $(13,41)$. Therefore, it is reasonable to predict that in obesity, the overexpression of OSM by immune cells, including macrophages, is acting on adipocytes to induce the secretion of inflammatory cytokines that promote infiltration and activation of more macrophages. This vicious cycle leads to a low-grade chronic inflammatory state that contributes to the development of insulin resistance (Figure 1). Moreover, in humans with obesity, OSM levels correlate positively with inflammatory markers and negatively with glucose transporter 4 (Glut4), suggesting that signaling through OSMRß could promote an immunological response in AT that impairs glucose homeostasis $(13,41)$.

In vivo experiments have demonstrated that mice lacking OSMR $\beta$, specifically in adipocytes, have significant increases in AT mass and OSM expression in fat, as well as enhanced adipose tissue inflammation, as compared to floxed littermate controls (36). The latter observation is unexpected, given that OSM signaling is known to promote inflammation. Although data from this study suggests that enhanced OSM-OSMR $\beta$ action in other AT cells, including immune populations, is consistent with the increased inflammatory immune response and insulin resistance phenotype in mice that lack OSM receptor specifically in adipocytes (36). Hence, by blocking OSM signaling in adipocytes via loss of the OSM receptor, the AT levels of OSM increase and promote metabolically unfavorable effects by acting on non-adipocyte cells present in AT.

One method to assess the importance of an endocrine mediator is to inhibit its activity with an immunoneutralization approach. Immunoneutralizing OSM is a complementary approach to knocking down the OSM receptor in adipocytes. In a recent study, we used high-fat fed C57BL/6J mice to induce OSM expression in AT and performed OSM immunoneutralization. Mice that received a specific anti-OSM antibody had improved inflammatory responses as compared to mice treated with a control IgG antibody (13). Moreover, OSM immunoneutralization normalized glucose levels and decreased expression of inflammatory genes in adipose tissue. However, OSM immunoneutralization did not significantly alter whole-body glucose tolerance or systemic insulin sensitivity (13). Although there are limitations with this approach, these studies underscore the need to understand the cell and tissue specific effects of both physiological and pathological functions of OSM.

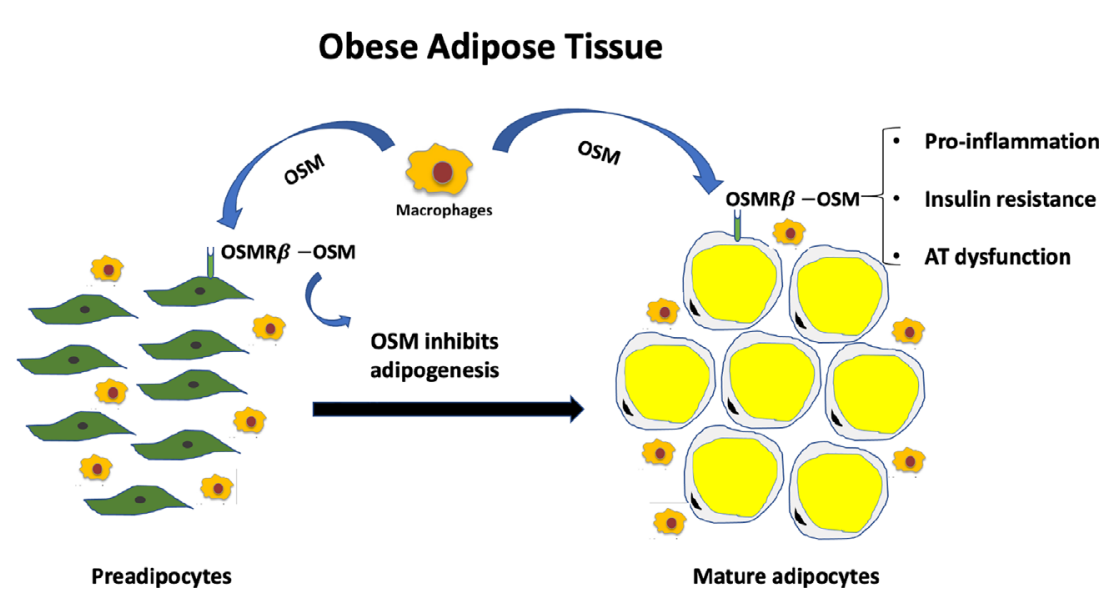

FIGURE 1 | Excess OSM and lack of adipocyte OSM signaling contributes to metabolic dysfunction. Less than half of the cells that comprise white adipose tissue depots are adipocytes. OSM is not produced in adipocytes, but in adipose tissue macrophages in conditions of obesity. OSM acts on preadipocytes to inhibit adipogenesis and acts on mature adipocytes to promote inflammatory signaling and insulin resistance in adipocytes. Both a loss of OSM signaling in adipocytes or excess OSM in adipose tissue promote systemic metabolic dysfunction. 
In addition to its functions in AT and association with obesity and Type 2 diabetes, OSM has been shown to play a role in a variety of disease conditions. Several studies have identified the OSM-OSMRß interaction as a potential therapeutic strategy for several pathological conditions. The selective inhibition of OSM by a neutralizing antibody suggested that paracrine actions of OSM in mammary fat played a role in breast cancer progression (34). In addition, OSM has been identified as a potential biomarker and therapeutic target in inflammatory bowel disease (35). The ability to target OSM in inflammatory bowel disease is important as up to $40 \%$ of patients do not respond to anti-TNF agents. Of note, an anti-OSM monoclonal antibody has recently been shown to be well tolerated in healthy subjects, and has demonstrated sufficient affinity to achieve target engagement in systemic circulation and target skin tissue, supporting further clinical investigation of antiOSM antibodies for inflammatory diseases (52).

\section{CONCLUSIONS}

In summary, OSM is a member of a large cytokine family, but its unique functions in adipocytes drive its effects on metabolic health. Levels of OSM and its receptor are elevated in AT in conditions of obesity and insulin resistance in mice and man (12). The roles of OSM have been elucidated using a wide range of approaches including global and adipocyte-specific knockout of the OSM receptor, as well as immunoneutralization of OSM in metabolically compromised mice. In AT, elevated levels of immune cell-derived OSM act on adjacent AT cells to inhibit preadipocyte differentiation and to enhance proinflammatory responses in adipocytes. Although adipose tissue OSM levels

\section{REFERENCES}

1. https://www.who.int/news-room/fact-sheets/detail/obesity-and-overweight.

2. González-Muniesa P, Mártinez-González MA, Hu FB, Després JP, Matsuzawa Y, Loos RJF, et al. Obesity. Nat Rev Dis Primers (2017) 3:17034. doi: 10.1038/ nrdp.2017.34

3. Sattar N, McInnes IB, McMurray JJV. Obesity Is a Risk Factor for Severe COVID-19 Infection: Multiple Potential Mechanisms. Circulation (2020) 142 (1):4-6. doi: 10.1161/CIRCULATIONAHA.120.047659

4. Apicella M, Campopiano MC, Mantuano M, Mazoni L, Coppelli A, Del Prato S. COVID-19 in people with diabetes: understanding the reasons for worse outcomes. Lancet Diabetes Endocrinol (2020) 8(9):782-92. doi: 10.1016/ S2213-8587(20)30238-2

5. Cummings DE, Cohen RV. Bariatric/Metabolic Surgery to Treat Type 2 Diabetes in Patients With a BMI <35 kg/m2. Diabetes Care (2016) 39(6):924-33. doi: $10.2337 / \mathrm{dc} 16-0350$

6. Richard AJ, White U, Elks CM, Stephens JM. Adipose Tissue: Physiology to Metabolic Dysfunction. In: Feingold KR, Anawalt B, Boyce A, Chrousos G, de Herder WW, Dungan K, et al. editors. Endotext. South Dartmouth (MA: MDText.com, Inc (2020).

7. Spalding KL, Arner E, Westermark PO, Bernard S, Buchholz BA, Bergmann O, et al. Dynamics of fat cell turnover in humans. Nature (2008) 453 (7196):783-7. doi: 10.1038/nature06902

8. Hotamisligil GS. Inflammation, metaflammation and immunometabolic disorders. Nature (2017) 542(7640):177-85. doi: 10.1038/nature21363

9. Villarroya F, Cereijo R, Gavaldà-Navarro A, Villarroya J, Giralt M. Inflammation of brown/beige adipose tissues in obesity and metabolic disease. J Intern Med (2018) 284(5):492-504. doi: 10.1111/joim.12803 correlate with systemic metabolic dysfunction, a loss of OSM receptor in adipocytes is also associated with impaired metabolic responses. This finding is consistent with a role for OSM signaling in healthy adipocytes and in AT homeostasis. Of note, there is a precedent for the contribution of inflammatory mediators in normal adipocyte function, as suppressing adipocyte inflammation impairs AT function and promotes insulin resistance $(53,54)$. Notably, the suppression of macrophage inflammation has little effect on obesity-induced insulin resistance, but inhibition of inflammatory signaling in adipocytes substantially effects systemic metabolic function (54). Inflammatory signaling in adipocytes plays a role in maintaining normal adipose tissue function and OSM signaling in adipocytes and adipose tissue is important for normal adipose tissue function and systemic metabolic health.

\section{AUTHOR CONTRIBUTIONS}

Both authors contributed equally to the preparation and editing of this review. All authors contributed to the article and approved the submitted version.

\section{FUNDING}

DS-I has been supported by grants CP15/00106 and FIS PI17/ 01455 from Carlos III National Institute of Health and European Regional Development Fund (ERDF).
10. Reilly SM and Saltiel AR. Adapting to obesity with adipose tissue inflammation. Nat Rev Endocrinol (2017) 13(11):633-43. doi: 10.1038/nrendo.2017.90

11. Sanchez-Infantes D, White UA, Elks CM, Morrison RF, Gimble JM, Considine RV, et al. Oncostatin $\mathrm{m}$ is produced in adipose tissue and is regulated in conditions of obesity and type 2 diabetes. J Clin Endocrinol Metab (2014) 99(2):E217-25. doi: 10.1210/jc.2013-3555

12. Stephens JM, Elks CM. Oncostatin M: Potential Implications for Malignancy and Metabolism. Curr Pharm Des (2017) 23:3645-57. doi: 10.2174/138161 2823666170704122559

13. Piquer-Garcia I, Campderros L, Taxerås SD, Gavaldà-Navarro A, Pardo R, Vila M, et al. A Role for Oncostatin M in the Impairment of Glucose Homeostasis in Obesity. J Clin Endocrinol Metab (2020) 105(3):e337-48. doi: 10.1210/clinem/dgz090

14. Rose-John S. Interleukin-6 Family Cytokines. Cold Spring Harb Perspect Biol (2018) 10(2):a028415. doi: 10.1101/cshperspect.a028415

15. Heinrich PC, Behrmann I, Haan S, Hermanns HM, Muller-Newen G, Schaper F. Principles of Interleukin (Il)-6-Type Cytokine Signalling and Its Regulation. Biochem J (2003) 374(Pt 1):1-20. doi: 10.1042/BJ20030407

16. Febbraio MA. Gp130 Receptor Ligands as Potential Therapeutic Targets for Obesity. J Clin Invest (2007) 117(4):841-9. doi: 10.1172/JCI30453

17. Mosley B, De Imus C, Friend D, Boiani N, Thoma B, Park LS, et al. Dual Oncostatin M (Osm) Receptors. Cloning and Characterization of an Alternative Signaling Subunit Conferring Osm-Specific Receptor Activation. J Biol Chem (1996) 271(51):32635-43. doi: 10.1074/jbc.271.51.32635

18. Rose TM, Bruce AG. Oncostatin M Is a Member of a Cytokine Family That Includes Leukemia- Inhibitory Factor, Granulocyte Colony-Stimulating Factor, and Interleukin 6. Proc Natl Acad Sci (1991) 88(19):8641-5. doi: 10.1073/pnas.88.19.8641

19. Rose TM, Lagrou MJ, Fransson I, Werelius B, Delattre O, Thomas G, et al. The genes for oncostatin M (OSM) and leukemia inhibitory factor (LIF) are tightly 
linked on human chromosome 22. Genomics (1993) 17(1):136-40. doi: 10.1006/ geno.1993.1294

20. Zarling JM, Shoyab M, Marquardt H, Hanson MB, Lioubin MN, Todaro GJ. Oncostatin M: A Growth Regulator Produced by Differentiated Histiocytic Lymphoma Cells. Proc Natl Acad Sci (1986) 83(24):9739-43. doi: 10.1073/pnas.83.24.9739

21. Kamiya A, Kinoshita T, Ito Y, Matsui T, Morikawa Y, Senba E, et al. Fetal liver development requires a paracrine action of oncostatin $\mathrm{M}$ through the gp130 signal transducer. EMBO J (1999) 18:2127-36. doi: 10.1093/emboj/18.8.2127

22. Nakamura K, Nonaka H, Saito H, Tanaka M, Miyajima A. Hepatocyte proliferation and tissue remodeling is impaired after liver injury in oncostatin M receptor knockout mice. Hepatology (2004) 39:635-44. doi: 10.1002/hep.20086

23. Henkel J, Gartner D, Dorn C, Hellerbrand C, Schanze N, Elz SR, et al. Oncostatin M produced in Kupffer cells in response to PGE2: possible contributor to hepatic insulin resistance and steatosis. Lab Invest (2011) 91:1107-17. doi: 10.1038/labinvest.2011.47

24. Wallace PM, MacMaster JF, Rouleau KA, Brown TJ, Loy JK, Donaldson KL, et al. Regulation of inflammatory responses by oncostatin M. J Immunol (2000) 164(10):5531.

25. Kubin T, Poling J, Kostin S, Gajawada P, Hein S, Rees W, et al. Oncostatin M is a major mediator of cardiomyocyte dedifferentiation and remodeling. Cell Stem Cell (2011) 9:420-32. doi: 10.1016/j.stem.2011.08.013

26. Gearing DP, Comeau MR, Friend DJ, Gimpel SD, Thut CJ, McGourty J, et al. The Il-6 Signal Transducer, Gp130: An Oncostatin M Receptor and Affinity Converter for the Lif Receptor. Science (1992) 255(5050):1434-7. doi: 10.1126/ science. 1542794

27. Ichihara $M$, Hara $T$, Kim $H$, Murate $T$, Miyajima A. Oncostatin $M$ and Leukemia Inhibitory Factor Do Not Use the Same Functional Receptor in Mice. Blood (1997) 90(5):2120.

28. Lindberg RA, Juan TS, Welcher AA, Sun Y, Cupples R, Guthrie B, et al. Cloning and Characterization of a Specific Receptor for Mouse Oncostatin M. Mol Cell Biol (1998) 18(6):3357-67. doi: 10.1128/mcb.18.6.3357

29. White UA, Stephens JM. Neuropoietin Activates Stat3 Independent of Lifr Activation in Adipocytes. Biochem Biophys Res Commun (2010) 395(1):48-50. doi: 10.1016/j.bbrc.2010.03.132

30. Brown TJ, Lioubin MN, Marquardt H. Purification and Characterization of Cytostatic Lymphokines Produced by Activated Human T Lymphocytes. Synergistic Antiproliferative Activity of Transforming Growth Factor Beta 1, Interferon-Gamma, and Oncostatin M for Human Melanoma Cells. J Immunol (1987) 139(9):2977-83.

31. Suda T, Chida K, Todate A, Ide K, Asada K, Nakamura Y, et al. Oncostatin M Production by Human Dendritic Cells in Response to Bacterial Products. Cytokine (2002) 17(6):335-40. doi: 10.1006/cyto.2002.1023

32. Hui W, Bell M, Carroll G. Detection of Oncostatin M in Synovial Fluid from Patients with Rheumatoid Arthritis. Ann Rheum Dis (1997) 56(3):184-7. doi: 10.1136/ard.56.3.184

33. Albasanz-Puig A, Murray J, Preusch M, Coan D, Namekata M, Patel Y, et al. Oncostatin M is expressed in atherosclerotic lesions: a role for Oncostatin M in the pathogenesis of atherosclerosis. Atherosclerosis (2011) 216(2):292-8. doi: 10.1016/j.atherosclerosis.2011.02.003

34. Lapeire L, Hendrix A, Lambein K, Van Bockstal M, Braems G, Van Den Broecke R, et al. Cancer-associated adipose tissue promotes breast cancer progression by paracrine oncostatin M and Jak/STAT3 signaling. Cancer Res (2014) 74(23):6806-19. doi: 10.1158/0008-5472.CAN-14-0160

35. West NR, Hegazy AN, Owens BMJ, Bullers SJ, Linggi B, Buonocore S, et al. Oncostatin $\mathrm{M}$ drives intestinal inflammation and predicts response to tumor necrosis factor-neutralizing therapy in patients with inflammatory bowel disease. Nat Med (2017) 23(5):579-89. doi: 10.1038/nm.4307

36. Elks CM, Zhao P, Grant RW, Hang H, Bailey JL, Burk DH, et al. Loss of Oncostatin M Signaling in Adipocytes Induces Insulin Resistance and Adipose Tissue Inflammation in Vivo. J Biol Chem (2016) 291(33):1706676. doi: $10.1074 /$ jbc.M116.739110

37. Danforth E. Failure of adipocyte differentiation causes type II diabetes mellitus? Nat Genet (2000) 26(1):13. doi: 10.1038/79111

38. Ouchi N, Parker JL, Lugus JJ, Walsh K. Adipokines in inflammation and metabolic disease. Nat Rev Immunol (2011) 11:85-97. doi: 10.1038/nri2921

39. White UA, Stewart WC, Mynatt RL, Stephens JM. Neuropoietin attenuates adipogenesis and induces insulin resistance in adipocytes. J Biol Chem (2008) 283(33):22505-12. doi: 10.1074/jbc.M710462200
40. Miyaoka Y, Tanaka M, Naiki T, Miyajima A. Oncostatin M inhibits adipogenesis through the RAS/ERK and STAT5 signaling pathways. J Biol Chem (2006) 281(49):37913-20. doi: 10.1074/jbc.M606089200

41. Sánchez-Infantes D, Cereijo R, Peyrou M, Piquer-Garcia I, Stephens JM, Villarroya F. Oncostatin $\mathrm{m}$ impairs brown adipose tissue thermogenic function and the browning of subcutaneous white adipose tissue. Obesity (Silver Spring) (2017) 25(1):85-93. doi: 10.1002/oby.21679

42. Komori T, Tanaka M, Senba E, Miyajima A, Morikawa Y. Lack of oncostatin $M$ receptor $\beta$ leads to adipose tissue inflammation and insulin resistance by switching macrophage phenotype. J Biol Chem (2013) 288(30):21861-75. doi: 10.1074/jbc.M113.461905

43. Komori T, Tanaka M, Senba E, Miyajima A, Morikawa Y. Deficiency of oncostatin $M$ receptor $\beta$ (OSMR $\beta$ ) exacerbates high-fat diet-induced obesity and related metabolic disorders in mice. J Biol Chem (2014) 289(20):1382137. doi: $10.1074 /$ jbc.M113.542399

44. Walker EC, McGregor NE, Poulton IJ, Solano M, Pompolo S, Fernandes TJ, et al. Oncostatin $\mathrm{M}$ promotes bone formation independently of resorption when signaling through leukemia inhibitory factor receptor in mice. J Clin Invest (2010) 120:582-92. doi: 10.1172/JCI40568

45. Luo P, Wang PX, Li ZZ, Zhang XJ, Jiang X, Gong J, et al. Hepatic Oncostatin M Receptor $\beta$ Regulates Obesity-Induced Steatosis and Insulin Resistance. Am J Pathol (2016) 186(5):1278-92. doi: 10.1016/j.ajpath. 2015.12.028

46. Dendorfer U, Oettgen P, Libermann TA. Multiple regulatory elements in the interleukin- 6 gene mediate induction by prostaglandins, cyclic AMP, and lipopolysaccharide. Mol Cell Biol (1994) 14:4443-54. doi: 10.1128/ mcb.14.7.4443

47. Cawston TE, Curry VA, Summers CA, Clark IM, Riley GP, Life PF. The role of oncostatin $\mathrm{M}$ in animal and human connective tissue collagen turnover and its localization within the rheumatoid joint. Arthritis Rheum (1998) 41:1760-71. doi: 10.1002/1529-0131(199810)41:10<1760::AID-ART8>3.0.CO;2-M

48. Repovic P, Benveniste EN. Prostaglandin E2 is a novel inducer of oncostatinM expression in macrophages and microglia. J Neurosci (2002) 22:5334-43. doi: 10.1523/JNEUROSCI.22-13-05334.2002

49. Hang H, Bailey JL, Elks CM. Oncostatin M Mediates Adipocyte Expression and Secretion of Stromal-Derived Factor 1. Biology (Basel) (2019) 8(1):19. doi: 10.3390/biology8010019

50. Peled A, Grabovsky V, Habler L, Sandbank J, Arenzana-Seisdedos F, Petit I, et al. The chemokine SDF-1 stimulates integrin-mediated arrest of CD34 (+) cells on vascular endothelium under shear flow. J Clin Invest (1999) 104:1199211. doi: $10.1172 / J C I 7615$

51. Scimone ML, Felbinger TW, Mazo IB, Stein JV, Von Andrian UH, Weninger W. CXCL12 mediates CCR7-independent homing of central memory cells, but not naive T cells, in peripheral lymph nodes. J Exp Med (2004) 199:111320. doi: $10.1084 /$ jem. 20031645

52. Reid J, Zamuner S, Edwards K, Rumley SA, Nevin K, Feeney M, et al. In vivo affinity and target engagement in skin and blood in a first-time-in-human study of an anti-oncostatin M monoclonal antibody. $\mathrm{Br} J$ Clin Pharmacol (2018) 84(10):2280-91. doi: 10.1111/bcp.13669

53. Wernstedt Asterholm I, Tao C, Morley TS, Wang QA, Delgado-Lopez F, Wang ZV, et al. Adipocyte inflammation is essential for healthy adipose tissue expansion and remodeling. Cell Metab (2014) 20(1):103-18. doi: 10.1016/ j.cmet.2014.05.005

54. Zhu Q, An YA, Kim M, Zhang Z, Zhao S, Zhu Y, et al. Suppressing adipocyte inflammation promotes insulin resistance in mice. Mol Metab (2020) 39:101010. doi: 10.1016/j.molmet.2020.101010

Conflict of Interest: The authors declare that the research was conducted in the absence of any commercial or financial relationships that could be construed as a potential conflict of interest.

Copyright () 2021 Sanchez-Infantes and Stephens. This is an open-access article distributed under the terms of the Creative Commons Attribution License (CC BY). The use, distribution or reproduction in other forums is permitted, provided the original author(s) and the copyright owner(s) are credited and that the original publication in this journal is cited, in accordance with accepted academic practice. No use, distribution or reproduction is permitted which does not comply with these terms. 